\title{
Homotopy Perturbation Method for Solving Reaction-Diffusion Equations
}

\author{
Yu-Xi Wang, Hua-You Si, and Lu-Feng Mo \\ School of Information Engineering, Zhejiang Forestry College, Lin'an 311300, Zhejiang, China \\ Correspondence should be addressed to Lu-Feng Mo, molufeng@126.com \\ Received 16 November 2007; Revised 11 February 2008; Accepted 27 February 2008 \\ Recommended by Paulo Gonçalves
}

The homotopy perturbation method is applied to solve reaction-diffusion equations. In this method, the trial function (initial solution) is chosen with some unknown parameters, which are identified using the method of weighted residuals. Some examples are given. The obtained results are compared with the exact solutions, revealing that this method is very efficient and the obtained solutions are of high accuracy.

Copyright ( 2008 Yu-Xi Wang et al. This is an open access article distributed under the Creative Commons Attribution License, which permits unrestricted use, distribution, and reproduction in any medium, provided the original work is properly cited.

\section{Introduction}

In this paper, we consider a reaction-diffusion process governed by the nonlinear ordinary differential equation [1]:

$$
y^{\prime \prime}(x)+y^{n}(x)=0, \quad 0<x<L,
$$

with boundary conditions

$$
y(0)=y(L)=0,
$$

where $y(x)$ represents the steady-state temperature for the corresponding reaction-diffusion equation with the reaction term $y^{n} ; n$ is the power of the reaction term (heat source), generally it follows $n>0, L$ is the length of the sample (heat conductor). The physical interpretation of (1.1) was given in [1].

Recently, various different analytical methods were applied to nonlinear equations arising in engineering applications, such as the homotopy perturbation method [2-10], and exp-function method [11,12], a complete review is available in [13]. This problem was studied 
by Lesnic using Adomian method [1], and by Mo [14] using variational method. In this paper, the homotopy perturbation method $[2,3,13]$ is applied to the discussed problem, and the obtained results show that the method is very effective and simple.

\section{Homotopy perturbation method}

In order to use the homotopy perturbation, we construct a homotopy in the form $[2,3,13]$

$$
(1-p)\left(y^{\prime \prime}-y_{0}^{\prime \prime}\right)+p\left(y^{\prime \prime}+y^{n}\right)=0
$$

with initial approximation

$$
y_{0}(x)=a x(1-x)=a x-a x^{2},
$$

where $a$ is an unkown constant to be further determined. It is obvious that (2.2) satisfies the boundary conditions.

We rewrite (2.1) in the form of

$$
y^{\prime \prime}+2 a-p\left(2 a-y^{n}\right)=0 .
$$

We suppose the solution of (2.3) has the form

$$
y(x)=y_{0}(x)+p y_{1}(x)+p^{2} y_{2}(x)+\cdots .
$$

Substituting (2.4) into (1.1) and equating the terms with the identical powers of $p$, we can solve $y_{0}, y_{1}, y_{2}, \ldots$ sequentially with ease. Setting $p=1$, we obtain the approximate solution of (1.1) in the form of

$$
y(x)=y_{0}(x)+y_{1}(x)+y_{2}(x)+\cdots .
$$

To illustrate its solution procedure, we consider some special cases.

Case $1(n=2)$. Under such case, we can easily obtain sequentially

$$
\begin{aligned}
& y_{0}^{\prime \prime}=-2 a, \\
& y_{1}^{\prime \prime}=2 a-y_{0}^{2}, \\
& y_{2}^{\prime \prime}=-2 y_{0} y_{1} .
\end{aligned}
$$

We, therefore, obtain the approximate solution in the form of

$$
y(x)=a x(1-x)+a x^{2}-a^{2}\left(\frac{1}{30} x^{6}-\frac{1}{10} x^{5}+\frac{1}{12} x^{4}\right)-\left(a-\frac{1}{60} a^{2}\right) x .
$$

In order to identify the unknown constant $a$ in (2.7), we apply the method of weighted residuals. Subsituting (2.7) into (1.1) results in the following residual:

$$
R(x, a)=y^{\prime \prime}(x)+y^{n}(x) .
$$

It is obvious that $R(0, a)=0$ and $R(1, a)=0$. We locate at $x=1 / 3$, and set $R(1 / 3, a)=0$, yielding the result

$$
a=45.4205 \text {. }
$$


Yu-Xi Wang et al.

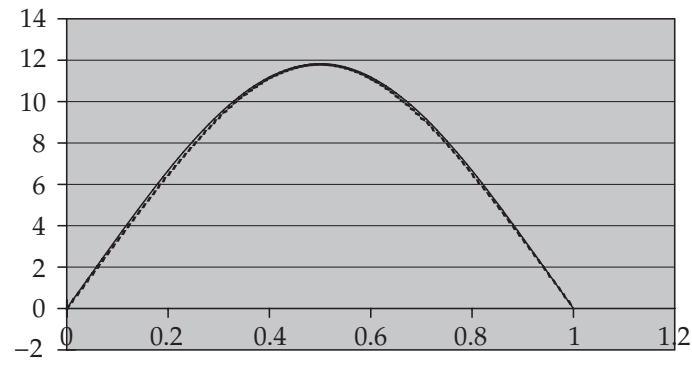

----- Exact solution

— Approximate solution

(a) $n=2$

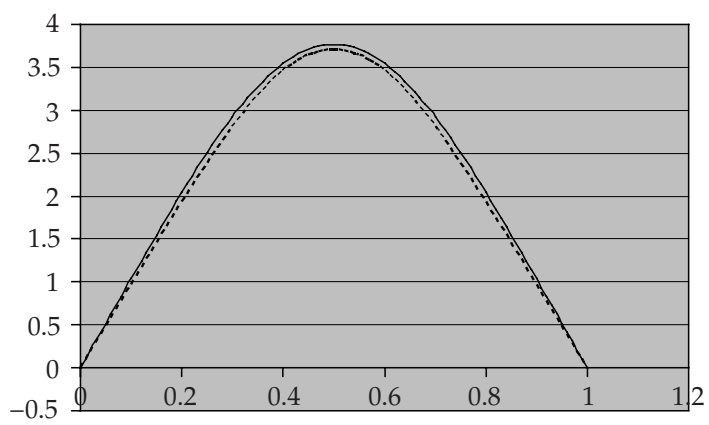

----- Exact solution

- Approximate solution

(b) $n=3$

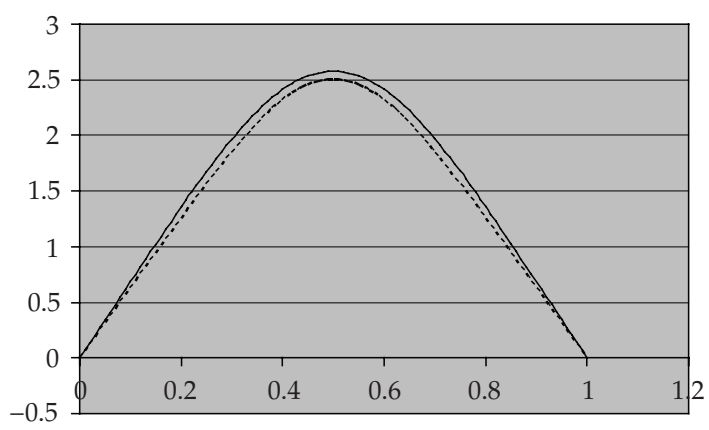

----- Exact solution

- Approximate solution

(c) $n=4$

Figure 1: Comparison of approximate solutions with exact ones. Continued line: approximate solution; discontinued line: exact solution. 
Case $2(n=3)$. The solution procedure is the same as that for Case 1 . We can easily obtain the following linear equations:

$$
\begin{array}{r}
a=14.2657, \\
y_{1}^{\prime \prime}=2 a-y_{0}^{3}, \\
y_{2}^{\prime \prime}=-3 y_{0}^{2} y_{1} .
\end{array}
$$

We obtain the following second-order approximate solution:

$$
y(x)=a x(1-x)+a x^{2}-a^{3}\left(-\frac{1}{56} x^{8}+\frac{1}{14} x^{7}-\frac{1}{10} x^{6}+\frac{1}{20} x^{5}\right)-\left(a-\frac{1}{280} a^{3}\right) x
$$

Similarly, we locate at $x=1 / 3$, and set $R(1 / 3, a)=0$ to identify the unknown constant, which reads $a=14.2657$.

Case $3(n=4)$. By the same manuplation as illustrated in above cases, we obtain

$$
\begin{gathered}
y_{0}^{\prime \prime}=-2 a, \\
y_{1}^{\prime \prime}=2 a-y_{0}^{4} \\
y_{2}^{\prime \prime}=-4 y_{0}^{3} y_{1} \\
y(x)=a x(1-x)+a x^{2}-a^{4}\left(\frac{1}{90} x^{10}-\frac{1}{18} x^{9}+\frac{3}{28} x^{8}-\frac{2}{21} x^{7}+\frac{1}{30} x^{6}\right)-\left(a-7.9410^{-4} a^{4}\right) x .
\end{gathered}
$$

Using the method of weighted residuals, we set $R(1 / 3 a)=0$, resulting in $a=9.6320$.

Figure 1 shows the remarkable accuracy of the obtained results.

\section{Conclusion}

The homotopy perturbation method deforms a complex problem under study to a simple problem routinely. If initial guess is suitably chosen, one iteration is enough, making the method a most attractive one. The method is of remarkable simplicity, while the obtained results are of utter accuracy on the whole solution domain. The method can be applied to various other nonlinear problems without any difficulty.

\section{References}

[1] D. Lesnic, "A nonlinear reaction-diffusion process using the Adomian decomposition method," International Communications in Heat and Mass Transfer, vol. 34, no. 2, pp. 129-135, 2007.

[2] J.-H. He, "New interpretation of homotopy perturbation method," International Journal of Modern Physics B, vol. 20, no. 18, pp. 2561-2568, 2006.

[3] J.-H. He, "A coupling method of a homotopy technique and a perturbation technique for non-linear problems," International Journal of Non-Linear Mechanics, vol. 35, no. 1, pp. 37-43, 2000.

[4] T. Ozis and A. Yildirim, "A comparative study of He's homotopy perturbation method for determining frequency-amplitude relation of a nonlinear oscillator with discontinuities," International Journal of Nonlinear Sciences and Numerical Simulation, vol. 8, no. 2, pp. 243-248, 2007. 
[5] A. Belendez, A. Hernandez, T. Belendez, et al., "Application of He's homotopy perturbation method to the Duffing-harmonic oscillator," International Journal of Nonlinear Sciences and Numerical Simulation, vol. 8, no. 1, pp. 79-88, 2007.

[6] X.-C. Cai, W.-Y. Wu, and M.-S. Li, "Approximate period solution for a kind of nonlinear oscillator by He's perturbation method," International Journal of Nonlinear Sciences and Numerical Simulation, vol. 7, no. 1, pp. 109-112, 2006.

[7] M. Dehghan and F. Shakeri, "Solution of an integro-differential equation arising in oscillating magnetic fields using He's homotopy perturbation method," Progress in Electromagnetics Research, vol. 78, pp. 361-376, 2008.

[8] F. Shakeri and M. Dehghan, "Inverse problem of diffusion equation by He's homotopy perturbation method," Physica Scripta, vol. 75, no. 4, pp. 551-556, 2007.

[9] M. Dehghan and F. Shakeri, "Solution of a partial differential equation subject to temperature overspecification by He's homotopy perturbation method," Physica Scripta, vol. 75, no. 6, pp. 778-787, 2007.

[10] D. D. Ganji and A. Sadighi, "Application of He's homotopy-perturbation method to nonlinear coupled systems of reaction-diffusion equations," International Journal of Nonlinear Sciences and Numerical Simulation, vol. 7, no. 4, pp. 411-418, 2006.

[11] S.-D. Zhu, "Exp-function method for the Hybrid-Lattice system," International Journal of Nonlinear Sciences and Numerical Simulation, vol. 8, no. 3, pp. 461-464, 2007.

[12] S.-D. Zhu, "Exp-function method for the discrete mKdV lattice," International Journal of Nonlinear Sciences and Numerical Simulation, vol. 8, no. 3, pp. 465-468, 2007.

[13] J.-H. He, "Some asymptotic methods for strongly nonlinear equations," International Journal of Modern Physics B, vol. 20, no. 10, pp. 1141-1199, 2006.

[14] L.-F. Mo, "Variational approach to reaction-diffusion process," Physics Letters A, vol. 368, no. 3-4, pp. 263-265, 2007. 


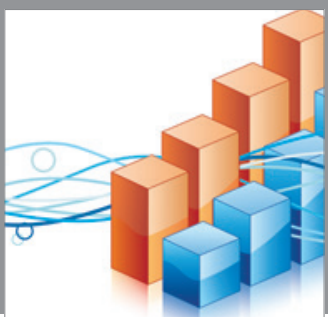

Advances in

Operations Research

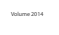

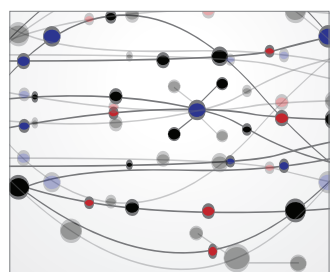

\section{The Scientific} World Journal
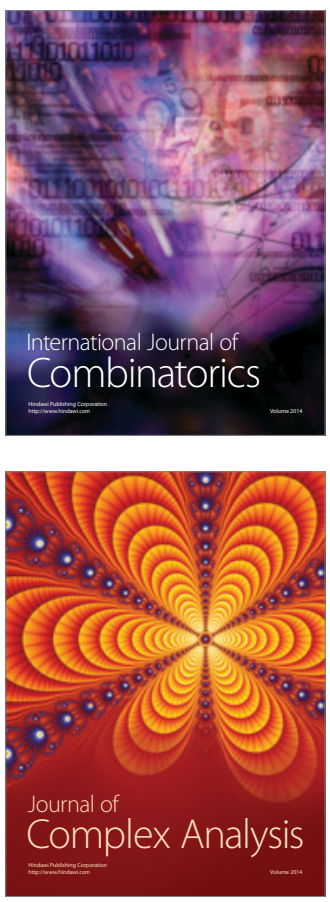

International Journal of

Mathematics and

Mathematical

Sciences
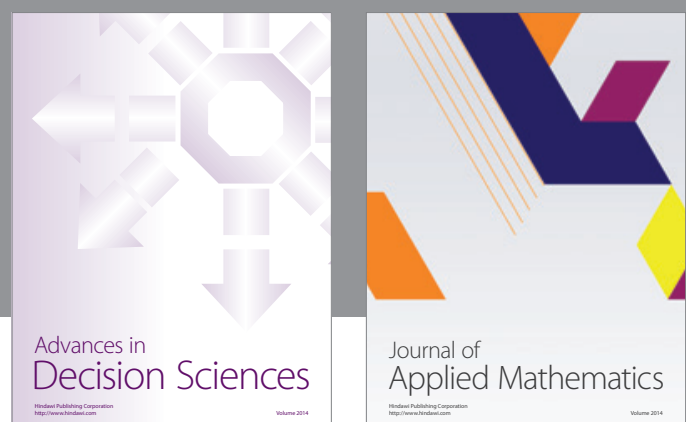

Journal of

Applied Mathematics
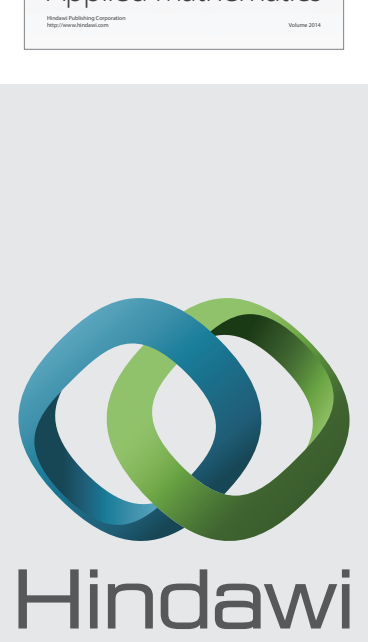

Submit your manuscripts at http://www.hindawi.com
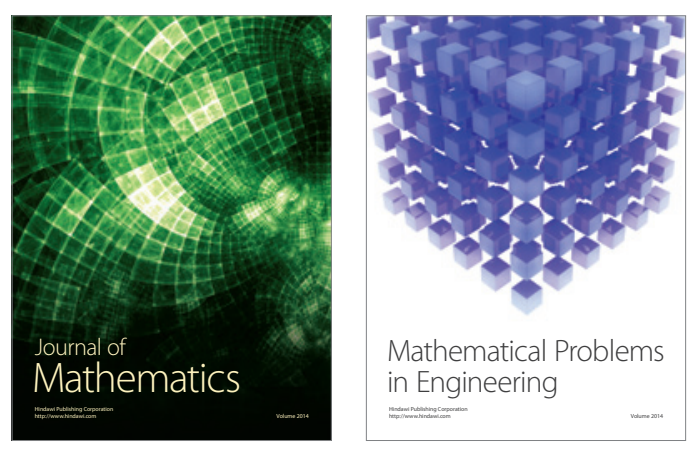

Mathematical Problems in Engineering
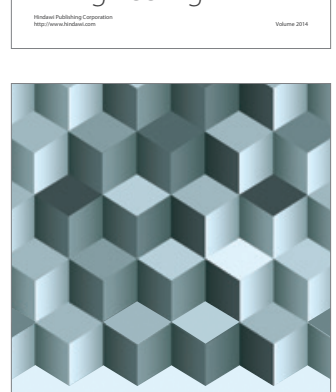

Journal of

Function Spaces
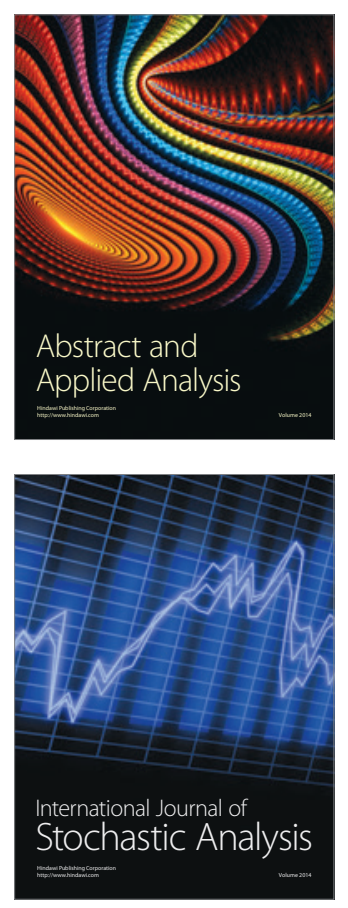

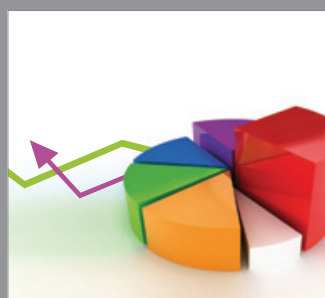

ournal of

Probability and Statistics

Promensencen
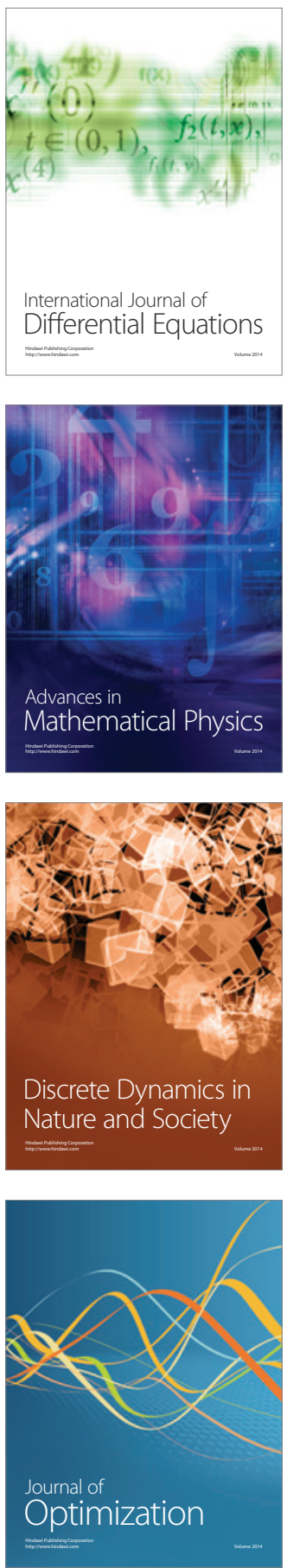